(Vol.VI, Maret 2015 )

\title{
HUBUNGAN PEMBERIAN ASI EKSKLUSIF DENGAN PERKEMBANGAN MOTORIK KASAR PADA ANAK USIA 6-36 BULAN
}

\author{
Supartini \\ Tenaga Pengajar Prodi DIII Kebidanan, Universitas PGRI Adi Buana Surabaya
}

\section{ABSTRAK}

ASI eksklusif merupakan makanan terbaik yang harus diberikan kepada bayi, karena didalamnya terkandung hampir semua zat gizi yang dibutuhkanoleh bayi. Sesuai keputusan Kep Men.Kes No. 450/Menkes/SK/IV/2004 ditetapkan pemberian ASI secara eksklusif sampai bayi berusia 6 bulan yang berarti bahwa bayi itu diberi ASI saja tanpa pemberian makanan lain sampai usia 6 bulan dan dianjurkan terus dilanjutkan sampai anak berusia 2 tahun. Hal tersebut sesuai dengan target sebesar $80 \%$ yang diamanatkan oleh Propenas (Program Pembangunan Nasional), karena banyak keuntungan dari pemberian ASI eksklusif yaitu anak akan cenderung mengalami perkembangan motorik kasar yang lebih cepat. Penelitian ini bertujuan untuk mengetahui hubungan pemberian ASI eksklusif dengan perkembangan motorik kasar pada anak usia 6-36 bulan di RW IV Kelurahan Simomulyo Wilayah Kerja Puskesmas Simomulyo Surabaya. Dalam penelitian ini digunakan metode analitik dengan desain penelitian Cross sectional yang pengambilan sampelnya dilakukan secara simple random sampling dengan jumlah sampel sebanyak 58 anak usia 6-36 bulan dengan menggunakan kuesioner dan wawancara serta observasi. Teknik analisis dengan perhitungan chi square. Hasil penelitian menunjukkan bahwa dari 58 responden, yang diberi Asi eksklusif sebanyak 26(44,83\%),sedangkan yang tidak diberi ASI eksklusif sebanyak $32(55,17 \%)$, berkembang sesuai umur sebanyak 46 anak(79,31\%), sedangkan yang tidak berkembang sesuai umur sebanyak 12 anak (20,69\%). Dari hasil uji chi-square didapatkan Ho ditolak.Maka dapat disimpulkan bahwa ada hubungan antara pemberian ASI eksklusif dengan perkembangan motorik kasar pada anak usia 6-36 bulan. Oleh sebab itu, perlu adanya penyuluhan tentang pentingnya pemberian ASI eksklusif secara terus menerus.

Kata kunci : ASI eksklusif, Perkembangan Motorik Kasar

\section{PENDAHULUAN}

ASI eksklusif merupakan makanan terbaik yang harus diberikan kepada bayi, karena di dalamnya terkandung hampir semua zat gizi yang dibutuhkan oleh bayi. Untuk melindungi dan mendorong peningkatan pemberian ASI, Pemerintah telah menerbitkan Kep. Men. Kes No.450/Menkes/SK/IV/2004 yang menetapkan pemberian ASI secara eksklusif sampai bayi berusia 6 bulan dan dianjurkan dilanjutkan sampai anak berusia 2 tahun dengan pemberian makanan tambahan yang sesuai. Hal tersebut sesuai dengan target sebesar
$80 \%$ yang diamanatkan oleh Propenas (Program Pembangunan Nasional). (Madjid, NA, 2004).

Pencapaian ASI Eksklusif di Jawa Timur masih rendah dan mengalami penurunan setiap waktu. Berdasarkan data dari Kabupaten/Kota diketahui bahwa cakupan bayi yang mendapat ASI Eksklusif di Jawa Timur tahun 2010 sebesar $30,72 \%$ dan yang tidak mendapat ASI Eksklusif sebesar $69,28 \%$. (Profil Kesehatan Jawa Timur 2009).

Pencapaian ASI Eksklusif di Kota Surabaya masih rendah dan mengalami penurunan setiap waktu. 
Berdasarkan data dari Puskesmas di Surabaya diketahui bahwa cakupan bayi yang mendapat ASI Eksklusif di Kota Surabaya tahun 2010 sebesar $26,90 \%$ dan yang tidak mendapat ASI Eksklusif sebesar $73,10 \%$ (Profil Kesehatan Jawa Timur 2010).

Bila dibandingkan dengan target pada Standart Pelayanan Minimal (SPM) di Kabupaten/Kota, di mana target pencapaian ASI Eksklusif adalah $80 \%$ pada tahun 2010 (Kepmenkes, 2004), juga berdasarkan target Indonesia Sehat 2010 bahwa persentase bayi yang mendapat ASI Eksklusif adalah 80\% (Depkes, 2003), maka pencapaian di Kota Surabaya tersebut masih sangat rendah.

Perkembangan motorik diartikan sebagai perkembangan dari unsur kematangan dan pengendalian gerak tubuh, dan perkembangan tersebut erat kaitannya dengan perkembangan pusat motorik di otak. Pada anak, gerakan ini dapat secara lebih jelas dibedakan antara gerakan kasar dan gerakan halus. Disebut gerakan kasar, bila gerakan yang dilakukan melibatkan sebagian besar bagian tubuh dan biasanya memerlukan tenaga karena dilakukan oleh otot-otot yang lebih besar. Dari hasil pengamatan terhadap bayi yang mendapat ASI eksklusif menunjukkan rata-rata terlihat gerakan motorik kasarnya lebih cepat (Hubertin, 2004).

Sedangkan dampak dari pertumbuhan dan perkembangan anak bila tidak mendapat ASI eksklusif tetapi diberi dengan susu formula adalah pertumbuhan badannya mungkin lebih besar, tapi imunitasnya tak sebaik bayi yang mendapat ASI eksklusif. Bila kurang menjaga hygienis terhadap susu botol maka banyak anak yang rentan terhadap penyakit, mudah terkena infeksi.

Penilaian tumbuh kembang periu dilakukan untuk menentukan apakah tumbuh kembang seorang anak berjalan normal atau tidak, baik dilihat dari segi medis maupun statistik. Anak yang sehat akan menunjukkan tumbuh kembang yang optimal apabila diberikan lingkungan bio-fisikpsikologis yang adekuat (Sutjiningsih, 1995).

Oleh sebab itu perlu dilakukan penelitian apakah pemberian ASI eksklusif ada hubungannya dengan perkembangan anak.

Rumusan Masalah adalah " Adakah hubungan pemberian ASI eksklusif dengan perkembangan motorik kasar pada anak usia 6-36 bulan di RW IV Kelurahan Simomulyo Wilayah Kerja Puskesmas Simomulyo Surabaya"?

Tujuan umum penelitian adalah mengetahui hubungan pemberian ASI eksklusif dengan perkembangan motorik kasar (gross motor) pada anak usia 6-36 bulan di RW IV Kelurahan Simomulyo Wilayah Kerja Puskesmas Simomulyo Surabaya. Sedangkan tujuan khusus penelitian adalah

1) Mengidentifikasi pemberian ASI eksklusif di RW IV Kelurahan Simomulyo Wilayah Kerja Puskesmas Simomulyo Surabaya.

2) Mengidentifikasi perkembangan motorik kasar Anak usia 6-36 bulan di RW IV Kelurahan Simomulyo Wilayah Kerja Puskesmas Simomulyo Surabaya.

3) Menganalisis hubungan pemberian ASI eksklusif dengan perkembangan motorik kasar (Gross Motor) pada Anak usia 636 bulan di RW IV Kelurahan Simomulyo Wilayah Kerja Puskesmas Simomulyo Surabaya.

\section{METODE PENELITIAN}

Penelitian ini merupakan penelitian analitik, yaitu menganalisa antara pemberian ASI Eksklusif dengan perkembangan motorik kasar anak usia 6-36 bulan. Pendekatan penelitian ini adalah cross sectional. 
Populasi dalam penelitian adalah anak berusia 6-36 bulan di RW IV Kelurahan Simomulyo Wilayah Kerja Puskesmas Simomulyo Surabaya. Sampel dalam penelitian ini sebanyak 58 anak usia 6-36 bulan. Sampel diambil dengan menggunakan teknik random sampling.

Pengumpulan data dalam pemberian ASI eksklusif menggunakan teknik wawancara terpimpin dengan bantuan instrumen penelitian yaitu kuesioner dan untuk mengetahui perkembangan motorik kasar anak usia 6-36 bulan menggunakan observasi dengan menggunakan check list berdasarkan usia anak. Analisa data menggunakan uji statistik chi square $\left(\mathrm{x}^{2}\right)$.

\section{HASIL DAN PEMBAHASAN Data Umum}

Berdasarkan hasil survey yang telah dilakukan pada anak usia 6-36 bulan, kami membagi sampel berdasarkan pengelompokan umur dan jenis kelamin didapatkan sebagai berikut:

Tabel 1 Distribusi Frekuensi Menurut Umur dan Jenis Kelamin pada Anak Usia 6-36 bulan di RW IV Kelurahan Simomulyo Wilayah Kerja Puskesmas Simomulyo Surabaya Periode OktoberNovember 2014

\begin{tabular}{|c|c|c|c|c|}
\hline \multirow{2}{*}{$\begin{array}{l}\text { Umur } \\
\text { (Bulan) }\end{array}$} & \multicolumn{2}{|c|}{$\begin{array}{l}\text { Jumlah Sesuai } \\
\text { Jenis Kelamin }\end{array}$} & \multirow[t]{2}{*}{ Jumlah } & \multirow[t]{2}{*}{$(\%)$} \\
\hline & Laki-laki & Perempuan & & \\
\hline $6-9$ & 1 & 5 & 6 & 10,34 \\
\hline $9-12$ & 3 & 1 & 4 & 6,90 \\
\hline $12-18$ & 10 & 8 & 18 & 31,03 \\
\hline $18-24$ & 5 & 4 & $a_{*}$ & 15,52 \\
\hline $\begin{array}{l}24-36 \\
36,21\end{array}$ & 5 & 16 & 21 & \\
\hline Jumlah & 24 & 34 & 58 & 100 \\
\hline
\end{tabular}

Berdasarkan tabel 5.1 diatas, dari 58 anak berusia 6 - 36 bulan terdiri dari kelompok usia 6 - 9 bulan sebanyak 6 anak $(10,34 \%)$, berusia 9
- 12 bulan sebanyak 4 (6,90\%), berusia 12 - 18bulan sebanyak 18 $(31,03 \%)$, berusia $18-24$ bulan sebanyak $9(15,52 \%)$ dan hampir separonya yakni $21(36,21 \%)$ berusia 24 - 36 bulan serta dari 58 anak usia 6 - 36 bulan yang berjenis kelamin lakilaki sebanyak $24(41,38 \%)$ dan perempuan $34(58,62 \%)$.

\section{Data Khusus \\ Pemberian ASI Eksklusif}

Tabel 2 Distribusi Frekuensi Pemberian ASI Eksklusif dan Umur pada Anak Usia 6-36 Bulan di RW IV Kelurahan Simomulyo Wilayah Kerja Puskesmas Simomulyo Surabaya Periode OktoberNovember 2014

\begin{tabular}{|c|c|c|c|c|c|c|}
\hline \multirow{2}{*}{$\begin{array}{l}\text { Umur } \\
\text { (Bulan) }\end{array}$} & \multicolumn{4}{|c|}{ Pemberian ASI EEksklusif } & \multirow{2}{*}{ Jumlah } & \multirow{2}{*}{$\%$} \\
\hline & $\mathrm{Ya}$ & $\%$ & Tidak & $\%$ & & \\
\hline $6-9$ & 3 & 50,00 & 3 & 50,00 & 6 & 100 \\
\hline $9-12$ & 2 & 50,00 & 2 & 50,00 & 4 & 100 \\
\hline $12-18$ & 11 & 61,11 & 7 & 38,89 & 18 & 100 \\
\hline $18-24$ & 4 & 44,44 & 5 & 55,56 & 9 & 100 \\
\hline $24-36$ & 6 & 28,57 & 15 & 71,43 & 21 & 100 \\
\hline Jumlah & 26 & 44,83 & 32 & 55,17 & 58 & 100 \\
\hline
\end{tabular}

Sumber : Data Primer Berdasarkan Kuesioner (Diolah Peneliti)

Berdasarkan tabel 2, pemberian ASI eksklusif di RW IV Kelurahan Simomulyo Wilayah Kerja Puskesmas Simomulyo Surabaya Periode Oktober - November 2014 mayoritas $(61,11 \%)$ berada pada kelompok usia 12 18bulan dan dari 58 anak usia 6 - 36 bulan yang diberikan ASI eksklusif sebanyak $26(44,83 \%)$, yang tidak diberikan ASI eksklusif sebanyak 32 $(55,17 \%)$ pada anak ini diberikan susu formula, pisang dan bubur sebelum usia 6 bulan.

\section{Perkembangan Motorik Kasar pada Anak Usia 6-36 Bulan}

Tabel 3. Distribusi Frekuensi Perkembangan Motorik Kasar dan Umur pada Anak Usia 636 Bulan di RW IV Kelurahan 
Simomulyo Wilayah Kerja Puskesmas Simomulyo Surabaya Periode Oktober November 2014

\begin{tabular}{|c|c|c|c|c|c|c|}
\hline \multirow{3}{*}{$\begin{array}{l}\text { Usia } \\
\text { (Bulan) }\end{array}$} & \multicolumn{4}{|c|}{ Perkembangan Motorik Kasar } & \multirow{3}{*}{\multicolumn{2}{|c|}{ Jumlah \% }} \\
\hline & $\begin{array}{l}\text { Sesuai } \\
\text { Umur }\end{array}$ & $\%$ & $\begin{array}{c}\text { Tidak } \\
\text { ssi umur }\end{array}$ & $\%$ & & \\
\hline & & & 8 & & & \\
\hline $6-9$ & 3 & 50,00 & 3 & 50,00 & 6 & 100 \\
\hline $9-12$ & 3 & 75,00 & 1 & 25,00 & 4 & 100 \\
\hline $12-18$ & 15 & 83,33 & 3 & 16,67 & 18 & 100 \\
\hline $18-24$ & 8 & 88,89 & 1 & 11,11 & 9 & 100 \\
\hline $24-36$ & 17 & 80,95 & 4 & 19,05 & 21 & 100 \\
\hline Jumlah & 46 & 79,31 & 12 & 20,69 & 58 & 100 \\
\hline
\end{tabular}

Berdasarkan tabel 3, diatas, Perkembangan motorik kasar sesuai dengan umur di RW IV Kelurahan Simomulyo Wilayah Kerja Puskesmas Simomulyo Surabaya mayoritas terdapat pada kelompok umur18- 24 bulan $(88,89 \%)$ dan dari 58 anak usia 6-36 bulan yang perkembangan motorik kasarnya sesuai dengan umur sebanyak $46(79,31 \%)$.

Hubungan Antara Pemberian ASI Eksklusif dengan Perkembangan Motorik Kasar pada Anak Usia 6-36 Bulan

Berdasarkan hasil penelitian, didapatkan hasil sebagai berikut :

Tabel 4 Hubungan antara Pemberian ASI Eksklusif dengan Perkembangan Motorik Kasar pada Anak Usia 6-36 Bulan di RW IV Kelurahan Simomulyo Wilayah Kerja Puskesmas Simomulyo Surabaya Periode Oktober - November 2014

\begin{tabular}{|c|c|c|c|}
\hline \multirow{2}{*}{$\begin{array}{c}\text { Pemberian } \\
\text { ASI } \\
\text { Eksklusif }\end{array}$} & \multicolumn{2}{|c|}{ Kemampuan Motorik } & \multirow[b]{2}{*}{ Jumlah } \\
\hline & Sesuai Umur & $\begin{array}{c}\text { Tidak sesuai } \\
\text { umur }\end{array}$ & \\
\hline Ya & 24 & 2 & 26 \\
\hline Tidak & & 10 & 32 \\
\hline Jumlah & 46 & 12 & 58 \\
\hline
\end{tabular}

Sumber : Data Primer Berdasarkan Kuesioner (Diolah Peneliti)
Dari Tabel 4 tersebut diatas didapatkan:

a. Responden yang mendapatkan ASI eksklusif dan perkembangan motorik kasar sesuai umur sebanyak 24 atau $20,62 \%$.

b. Responden yang mendapatkan ASI eksklusif dan perkembangan motorik kasar tidak sesuai umur (mengalami keterlambatan) sebanyak 2 atau 5,38\%.

c. Responden yang tidak mendapatkan ASI eksklusif dan perkembangan motorik kasar sesuai umur sebanyak 22 atau $25,38 \%$.

d. Responden yang tidak mendapatkan ASI eksklusif dan perkembangan motorik kasar tidak sesuai umur (mengalami keterlambatan) sebanyak 10 atau $6,62 \%$.

Pada penelitian ini menggunakan uji chi kuadrat atau $x^{2}$ dengan langkahlangkah sebagai berikut :

1. Mencari Frekuensi Harapan (Fe) pada setiap sel dengan rumus :

$$
F e=\frac{\left(\sum f k X \sum f b\right)}{\sum T}
$$

Keterangan

$$
\begin{aligned}
& \mathrm{Fe} \quad \text { : Frekuensi yang } \\
& \sum f k \quad \text { Jumlah frekuensi } \\
& \text { pada kolom } \\
& \sum f b \quad: \text { Jumlah frekuensi } \\
& \text { pada baris } \\
& \sum T \quad \text { : Jumlah keseluruhan } \\
& \text { baris dan kolom } \\
& F e(1)=\frac{(46 \times 26)}{58}=\frac{1196}{58}=20,62 \\
& F e(2)=\frac{(12 \times 26)}{58}=\frac{312}{58}=5,38
\end{aligned}
$$




$$
\begin{aligned}
& F e(3)=\frac{(46 \times 32)}{58}=\frac{1472}{58}=25,38 \\
& F e(4)=\frac{(12 \times 32)}{58}=\frac{384}{58}=6,62
\end{aligned}
$$

2. Dilanjutkan dengan uji chi kuadrat atau $x^{2}$ untuk mengestimasi atau mengevaluasi frekuensi yang diselidiki atau menganalisis hasil observasi untuk mengetahui, apakah terdapat hubungan. Mencari nilai chi kuadrat dengan rumus :

$$
\begin{aligned}
& x^{2}=\sum \frac{(f o-f e)^{2}}{f e} \\
& x^{2}{ }_{(1)}=\frac{(24-20,62)^{2}}{20,62}=0,55 \\
& x_{(2)}^{2}=\frac{(2-5,38)^{2}}{5,38}=2,12 \\
& x_{(3)}^{2}=\frac{(22-25,38)^{2}}{25,38}=0,45 \\
& x_{(4)}^{2}=\frac{(10-6,62)^{2}}{6,62}=1,73 \\
& x=x_{(1)}^{2}+x_{(2)}^{2}+x_{(3)}^{2}+x_{(4)}^{2}=4,85
\end{aligned}
$$

3. Mencari nilai $x^{2}$ dengan rumus :

$d k=(k-1)(b-1)$

Keterangan :

$\mathrm{k} \cdot$ : Banyaknya kolom

b : Banyaknya baris

$d k=(2-1)(2-1)=1$

Menurut tabel, harga $x^{2}$ dengan $\alpha=0,05$ dan $\mathrm{df}=1$ adalah 3,84

Hipotesis

$\mathrm{H}_{0}$ : Tidak ada hubungan antara pemberian ASI eksklusif dengan perkembangan motorik kasar pada anak usia 6-36 bulan di RW IV Kelurahan Simomulyo Wilayah Kerja Puskesmas Simomulyo Surabaya.
$\mathrm{H}_{1}$ : Ada hubungan antara pemberian ASI eksklusif dengan perkembangan motorik kasar pada anak usia 6-36 bulan di RW IV Kelurahan Simomulyo Wilayah Kerja Puskesmas Simomulyo Surabaya.

Oleh karena harga uji statistic $x^{2}$ $=4,85$ lebih besar dari harga $x^{2}=$ 3,84 tabel, maka $\mathrm{H}_{1}$ diterima pada taraf signifikansi 0,05 . Dan dapat disimpulkan bahwa ada hubungan antara pemberian ASI eksklusif dengan perkembangan motorik kasar pada anak usia 6-36 bulan di RW IV Kelurahan Simomulyo Wilayah Kerja Puskesmas Simomulyo Surabaya.

\section{PEMBAHASAN}

Berdasarkan penelitian yang telah dilakukan maka akan diuraikan hubungan antara pemberian ASI eksklusif dan perkembangan motorik kasar pada anak usia 6-36 bulan di RW IV Kelurahan Simomulyo Wilayah Kerja Puskesmas Simomulyo Surabaya Periode Oktober November 2014.

\section{Pemberian ASI eksklusif Pada Anak Usia 6-36 Bulan}

Hasil penelitian menunjukkan bahwa dari 58 responden dengan usia 6-36 bulan yang diberi ASI eksklusif sebanyak $26(44,83 \%)$. Hasil ini masih lebih kecil dari yang tidak diberi ASI eksklusif sebanyak $32 \quad(55,17 \%)$. Menurut Moody, Jane (2006) dalam survey pemberian makan bayi tahun 1990 , sebanyak $32 \%$ ibu yang bayinya disusui, tetapi juga menerima susu formula di Rumah Sakit, berhenti menyusui dalam dua minggu pertama, dibandingkan $90 \%$ ibu yang bayinya tidak menerima susu formula. Survey ini sesuai dengan hasil yang didapatkan bahwa ibu-ibu cenderung masih memberikan makanan atau minuman lain selain air susu ibu. Belum adanya rasa percaya dan 
kemampuan ibu untuk menyusui bayinya mungkin karena ibu berkeyakinan bahwa air susunya tidak dapat memuaskan kebutuhan bayi.

Berdasarkan target yang ditetapkan oleh pemerintah sebesar $80 \%$ untuk pemberian ASI eksklusif, maka dalam hal ini masih belum tercapai sesuai dengan harapan. Peran Bidan di Rumah Sakit hendaknya mulai menyadari bahwa mereka berperan penting didalam membantu seorang ibu untuk menyusui dengan benar. Lingkungan Rumah Sakit atau tempat persalinan ibu, tidak selalu merupakan tempat yang terbaik untuk belajar menyusui.

Pada kelompok usia 12-18 bulan yang terlihat pada tabel 5.2 adalah mayoritas pemberian ASI eksklusif dari usia kelompok yang lain yaitu 11 $(61,11 \%)$ disini kemungkinan adalah ibu-ibu yang pernah mendapat nasihat dan informasi yang jelas dan konsisten berdasarkan kebijakan yang disepakati. Dan pada kelompok usia 24-36 bulan adalah mayoritas yang tidak diberi ASI eksklusif sebanyak 15 $(71,43 \%)$, kemungkinan penyebab ada beberapa faktor antara lain adanya kesulitan waktu menyusui baik pada ibu maupun penyulit pada bayi, kesibukan ibu yang bekerja sehingga mereka memberikan susuformula atau makanan tambahan ataupun karena pengetahuan ibu yang kurang tentang pentingnya ASI eksklusif.

\section{Kemampuan Motorik Kasar pada Anak Usia 6-36 bulan}

Berdasarkan kemampuan motorik kasar pada anak usia 6-36 bulan pada tabel 3 menunjukkan bahwa dari 58 responden mayoritas perkembangan motorik kasarnya sesuai dengan umur sebanyak 46 (79,31\%). Hasil ini masih lebih besar daripada yang tidak sesuai umur (mengalami keterlambatan) sebanyak 12 (20,69\%). Menurut Depkes RI (1999) yang dimaksud dengan tumbuh kembang optimal adalah tercapainya proses tumbuh kembang yang sesuai dengan potensi yang dimiliki oleh anak. Untuk mendapatkan tumbuh kembang yang optimal menurut Depkes RI (1999) perlu dilakukan stimulasi tumbuh kembang yang artinya bahwa, anak tersebut harus mendapat perangsangan dan latihan terhadap anak yang datangnya dari lingkungan luar, misalnya latihan terhadap kemampuan motorik, kemampuan bahasa dan kognitif, serta kemampuan bersosialisasi dan mandiri.

Periode penting dalam tumbuh kembang anak adalah masa Balita, karena pada masa ini pertumbuhan dasar akan mempengaruhi dan menentukan perkembangan anak selanjutnya. Pada usia $6-36$ bulan ini perkembangan kemampuan berbahasa, kreativitas, kesadaran sosial, emosional dan intelegensi berjalan sangat cepat dan merupakan landasan perkembangan berikutnya. Bahkan ada sarjana yang menyatakan bahwa "The Child is the Father of the Man" sehingga setiap kelainan atau penyimpangan sekecil apapun apabila tidak terdeteksi apalagi tidak ditangani dengan baik akan mengurangi kualitas sumber daya manusia kelak kemudian hari.

Pada tabel 3 terlihat bahwa pada usia 6-36 bulan ada yang mengalami keterlambatan dalam perkembangan motorik kasar yaitu 12 (20,69\%). Kemungkinan hal ini sesuai dengan apa yang dikatakan Soetjiningsih (1995) bahwa dalam perkembangan anak terdapat masa kritis, dimana diperlukan rangsangan atau stimulasi yang berguna agar potensi berkembang, sehingga perlu mendapat perhatian. Disamping stimulasi atau rangsangan yang tidak kalah penting adalah kebutuhan akan nutrisi yang adekuat dan seimbang. Zat-zat nutrisi adalah termasuk pembangun tubuh yang mempunyai 
pengaruh terhadap pertumbuhan dan perkembangan terutama pada tahuntahun pertama kehidupan dimana anak sedang mengalami pertumbuhan yang sangat pesat terutama pertumbuhan otak.

Bila bayi usia 0-6 bulan diberi ASI eksklusif maka itu sudah cukup untuk memenuhi kebutuhan anak. Komposisi ASI dan berbagai faktor pertumbuhan yang ada didalam ASI sangat menentukan proses pertumbuhan dan perkembangan jaringan otak bayi. Apabila itu ada penyimpangan maka adalah suatu indicator terhadap adanya kelainan akibat penyakit, hormonal dan gizi kurang.

Pola perkembangan anak adalah sama pada semua anak, tetapi kecepatannya berbeda antara anak yang satu dengan lainnya, sebagai contoh anak akan belajar duduk sebelum belajar berjalan, tetapi umur saat anak belajar duduk atau berjalan berbeda antara anak satu dengan lainnya.

3. Hubungan antara Pemberian ASI Eksklusif dengan Perkembangan Motorik Kasar pada Anak Usia 6-36 bulan.

Berdasarkan hasil penelitian pada tabel 4 menunjukkan bahwa yang diberikan ASI eksklusif dan kemampuan motorik kasar sesuai dengan umur pada anak usia 6-36 bulan adalah $24(20,62 \%)$, sedangkan yang tidak diberikan ASI eksklusif dan perkembangan motorik kasar sesuai umur sebanyak 22 (25.38\%). Perkembangan motorik dipengaruhi oleh banyak faktor antara lain faktor genetik, gizi, penyakit, emosi, sosial ekonomi, latihan, stimulasi. Responden yang diberikan ASI eksklusif dengan perkembangan motorik kasar mengalami keterlambatan sebanyak 2 (5,38\%) dan yang tidak diberikan ASI eksklusif dengan perkembangan motorik kasar mengalami keterlambatan sebanyak $10(6,62 \%)$. Keadaan ini menunjukkan bahíwa pemberian ASI eksklusif ada hubungannya dengan perkembangan motorik yang sesuai dengan usia anak. Hal ini dibuktikan dengan hasil penelitian yang menunjukkan uji chisquare, bahwa $X^{2}$ hitung $>\quad X^{2}$ tabel $(4,85>3,84)$ sehingga $H_{0}$ ditolak. Jadi kesimpulannya kedua variable tersebut menunjukkan bahwa ada hubungan antara pemberian ASI eksklusif dengan perkembangan motorik kasar pada anak usia 6-36 bulan.

Dapat diketahui disini bahwa hasil penelitian ini sesuai dengan apa yang diungkapkan Hubertin (2004) bahwa anak yang diberi ASI sampai 6 bulan akan jauh lebih sehat dari bayi yang menyusui $A S I$ hanya sampai 4 bulan, dan frekuensi terkena diare jauh lebih kecil sehingga kesehatan bayi akan lebih baik dan juga menurunkan kemungkinan bayi terkena infeksi telinga, flu, dan penyakit alergi. Dengan demikian memungkinkan anak akan bertumbuh dan berkembang secara optimal sesuai dengan tahapan-tahapannya. Dari hasil pengamatannya juga disebutkan bahwa rata-rata menunjukkan gerakan motorik kasarnya lebih cepat.

\section{SIMPULAN DAN SARAN}

Berdasarkan hasil penelitian dapat disimpulkan sebagai berikut:

1. Pemberian ASI eksklusif pada anak usia 6-36 bulan di RW IV Kelurah SimomulyoWilayah Kerja Puskesmas Simomulyo Surabaya sebanyak $44,83 \%$

2. Perkembangan motorik kasar pada anak usia 6-36 bulan di RW IV Kelurahan Simomulyo Wilayah Kerja Puskesmas Simomulyo Surabaya $81,03 \%$ sesuai dengan umur.

3. Ada hubungan pemberian ASI eksklusif dengan perkembangan motorik kasar pada anak usia 6-36 
bulan di RW IV Kelurahan Simomulyo Wilayah Kerja Puskesmas Simomulyo Surabaya.

Berdasarkan pada hasil penelitian, maka disarankan para ibu-ibu untuk memberikan ASI eksklusif pada bayi umur 0-6 bulan tanpa disertai pemberian makanan lain, petugas kesehatan dan kader berperan aktif dalam memberikan penyuluhan tentang pentingnya pemberian ASI eksklusif dan perkembangan motorik kasar serta menstimulus perkembangan anak mereka.

\section{DAFTAR PUSTAKA}

Dinkes. Propinsi Dati I Jatim. Patokan Aspek Perkembangan Balita, Surabaya

Depkes. RI. 1997. Pedoman Deteksi Dini Tumbuh Kembang Balita. Jakarta

Depkes. RI. 1999. Petunjuk pelaksanaan Deteksi Dini tumbuh kembang balita. Bagi Petugas Puskesmas.

Hidayat, Aziz Alimul. 2007. Metode Penelitian Kebidanan dan Teknik Analisa Data. Jakarta : Salemba Medika

IDAI. 2002. Tumbuh kembang Anak dan Remaja, Buku Ajar I, Edisi I. Jakarta : Sagung Seto

Madjid, Nurainy Et all. 2004. Peningkatan Kualitas Sumber Daya Manusia Indonesia Melalui Pemberian ASI. Pertemuan Pra Pertemuan IImiah Tahun XIV POGI. Bandung

Moody, Jane. Britten, Jane, dan Hogg, Karen. 2006. Menyusui cara mudah, praktis, dan Nyaman. Jakarta : Arcan.

Notoatmodjo. Soekidjo. 2002. Metodologi Penelitian Kesehatan. Jakarta : Rineka Cipta

Perinasia. 2007. Bahan Bacaan Manajemen Laktasi, Edisi I. Jakarta : Program Manajemen Laktasi

Soetjiningsih. 1995. Tumbuh Kembang Anak.Jakarta : EGC

Sri Purwanti. Hubertin. 2004. Konsep Penerapan ASI Eksklusif. Jakarta

EGC 